\title{
Current needs, the future of adolescents and young adults having sustained a moderate or severe Traumatic Brain Injury (TBI) and the potential of their social participation
}

\author{
Sirois Katia ${ }^{1,2^{\star}}$, Boucher Normand ${ }^{1,2}$, Lepage Céline ${ }^{1,2}$ \\ ${ }^{1}$ Rehabilitation Institute of Quebec City (IRDPQ), Quebec City, Canada; ${ }^{*}$ Corresponding Author: katia.sirois@psy.ulaval.ca \\ ${ }^{2}$ Centre for Interdisciplinary Research on Rehabilitation and Social Integration (CIRRIS), Quebec City, Canada
}

Received 19 September 2013; revised 1 November 2013; accepted 14 November 2013

Copyright (c) 2014 Sirois Katia et al. This is an open access article distributed under the Creative Commons Attribution License, which permits unrestricted use, distribution, and reproduction in any medium, provided the original work is properly cited. In accordance of the Creative Commons Attribution License all Copyrights @ 2014 are reserved for SCIRP and the owner of the intellectual property Sirois Katia et al. All Copyright (C) 2014 are guarded by law and by SCIRP as a guardian.

\section{ABSTRACT}

The general objective of this study is to identify the specific needs of youths who have suffered a moderate or severe traumatic brain injury (TBI) and their levels of life habit accomplishments. The secondary objective aims to identify how they view themselves in the future with regard to their life habits. Eighteen young persons with moderate or severe TBls aged 14 to $20 \mathrm{com}$ pleted questionnaires based on the Life-Habits questionnaire and elaborated on their current level of satisfaction and their visions of the future. Teenagers reported that maintaining good interpersonal relationships, being autonomous, fulfilling their responsibilities, warding off loneliness, as well as being supported in their efforts to reach a satisfying response to their needs and concerns were their highest priorities. In order to increase their satisfaction related to life habits they suggest improving external factors, such as information concerning TBIs to their entourage. They see themselves as complete social participants in the future. Youths with moderate or severe TBIs identified their needs and envisioned their future to be like that of any other teenager and young adult. They hope to start a family and find a good job. They also identified strategies to improve their life habits.

\section{KEYWORDS}

Traumatic Brain Injury; Adolescents;

Rehabilitation; Social Participation

\section{INTRODUCTION}

Sustaining a traumatic brain injury (TBI) during adolescence has a significant, immediate [1,2] and long-term impact on the accomplishment of life habits [3,4]. Adolescence is recognized by all adolescents as a period of both psychological and physical changes requiring adaptation. A TBI becomes one of several personal characteristics of a teenager and influences his or her needs. In this regard, adolescents have needs that differ from those of adults, yet they have similar life habits and concerns, e.g. occupational choices, social and residential independence, leisure activities, love life, etc. [5,6]. For children and adolescents who sustained brain injuries, the needs for support vary according to the age of the individual [7].

It has been known for some time that a moderate or severe TBI does not lead to the same consequence profile nor the same care as a mild TBI and that the consequences of a TBI increase with its severity $[8,9]$. Teenagers who have suffered a moderate or severe TBI generally find themselves coping with cognitive difficulties such as attention deficit, working memory, executive functions, and inhibition, as well as behavioral problems such as impulsivity; all of which influence almost all spheres of their lives [10-12]. Life habits comprise everyday life activities such as going to bed, and getting up, eating a meal, etc., while other activities are executed on a more or less regular basis, such as shopping, budgeting, educating one's children, etc., and they have an impact on social participation [13]. These sequels act as obstacles to occupational choices, social and residential independence, leisure activities, and love life $[5,14]$. 
To the best of our knowledge, studies examining the needs of adolescents with TBIs have been conducted either among teenagers with mostly mild TBIs [15] among teenagers older than 16 years who suffered a moderate or severe TBI and/or their parents [16-21] or with patients in acute health services [22]. Among adolescents who have suffered a mild TBI, the identified priority needs relate to obtaining structured health services that acknowledge their distinct character, information appropriate for symptom management, other relevant information and support, as well as clinicians who recognize their distinct character [15]. Surveys and studies of the longitudinal needs of clients who are 16 and older have identified needs that relate principally to longterm psychological support learning to cope with cognitive impairments that impact their studies, employment and interpersonal relationships [19,20].

It appears as though few studies have involved speaking directly to teenagers and young adult clients who have suffered a moderate or severe TBI in order to specifically identify their needs with regard to life habit accomplishments. Generally, the previously documented needs relate to services or disabilities, yet few have examined life habit performance, life habit performance satisfaction, and strategies to improve same.

Thus, the herein study, in continuity with previous studies, aims to identify the needs of adolescents who have suffered a moderate or severe TBI, by questioning adolescents themselves regarding their needs and the link between those needs and life habit accomplishment, despite altered cognitive functioning due to a moderate or severe TBI. The general objective of this study is to identify the specific needs of adolescents and young adult clients (14 to 20 years of age) who have suffered a moderate or severe TBI with regard to the level of life habit accomplishment and the strategies that enable them to improve those life habits, the performance levels of the latter, being the most unsatisfying. The secondary objective aims to identify how teenagers who have suffered a moderate or severe TBI view themselves in the future with regard to life habit accomplishments. This information appears to be primordial in order to improve the structure of services offered to this clientele that are oriented towards meeting the needs identified by the clients themselves and that favor the accomplishment of life habits enabling them to achieve the future they desire.

\section{METHOD}

\subsection{Design}

This exploratory study involves a mixed design: both quantitative and qualitative. The project was approved by the ethics committee of the Institut de réadaptation en déficience physique de Québec (IRDPQ) [Quebec Institute of Physical Rehabilitation].

\subsection{Participants}

The sample was comprised of adolescents aged 14 to 21 who are thus in the "early" to "late" stages of adolescence which ends at age 21 [2]. Of this sample, 28\% were girls, and $72 \%$ were boys, which mirrors the 2 boys to 1 girl statistics related to the risk of experiencing a TBI in the province of Quebec, Canada [23]. Participants with an additional syndrome such as Down's syndrome or severe impairments such as cerebral palsy that were present before the trauma, were excluded from the study. The socio-demographic data and the medical characteristics of the sample are presented in Figure 1. The 18 study participants had all completed the acute hospitalization and intensive functional rehabilitation phase and had returned to their home environment. However, on occasion they were continuing to attend at a physical rehabilitation center in the Quebec City $(\mathrm{n}=15)$ or Chaudière-Appalaches $(n=3)$ regions of Quebec, Canada.

At the outset, the potential participants received an information letter inviting them to participate in the project. In case of interest, they were then contacted by the primary researcher. The project was explained to them and once they agreed to participate, a written consent form was signed by the youth, if 18 years and older, or by a parent. Each participant younger than 18 years of age was also invited to sign the consent form. Twenty-eight percent of those having received the invitation agreed to participate.

\subsection{Instruments}

Each participant was interviewed individually for a period of 90 to 120 minutes in their home, school or rehabilitation centre, according to their preference. During that time, they responded to a 5-part questionnaire measuring the level of life habit accomplishments, life habit accomplishment satisfaction levels, as well as strategies to improve the level of life habit performance and satisfaction. Participants were also asked about how they envision their performance on life habits in ten years. The interview questionnaire is based on the Assessment of Life Habits (LIFE-H) for children and adolescents [24] and the general LIFE-H [25]. The LIFE-H was developed to evaluate several life habits relating to the social participation of people with disabilities, regardless of their underlying deficits. It documents the level of performance on life habits, which are defined as common activities and social roles valued by people with disabilities and their sociocultural environment according to their personal characteristics, i.e. age, sex, sociocultural 


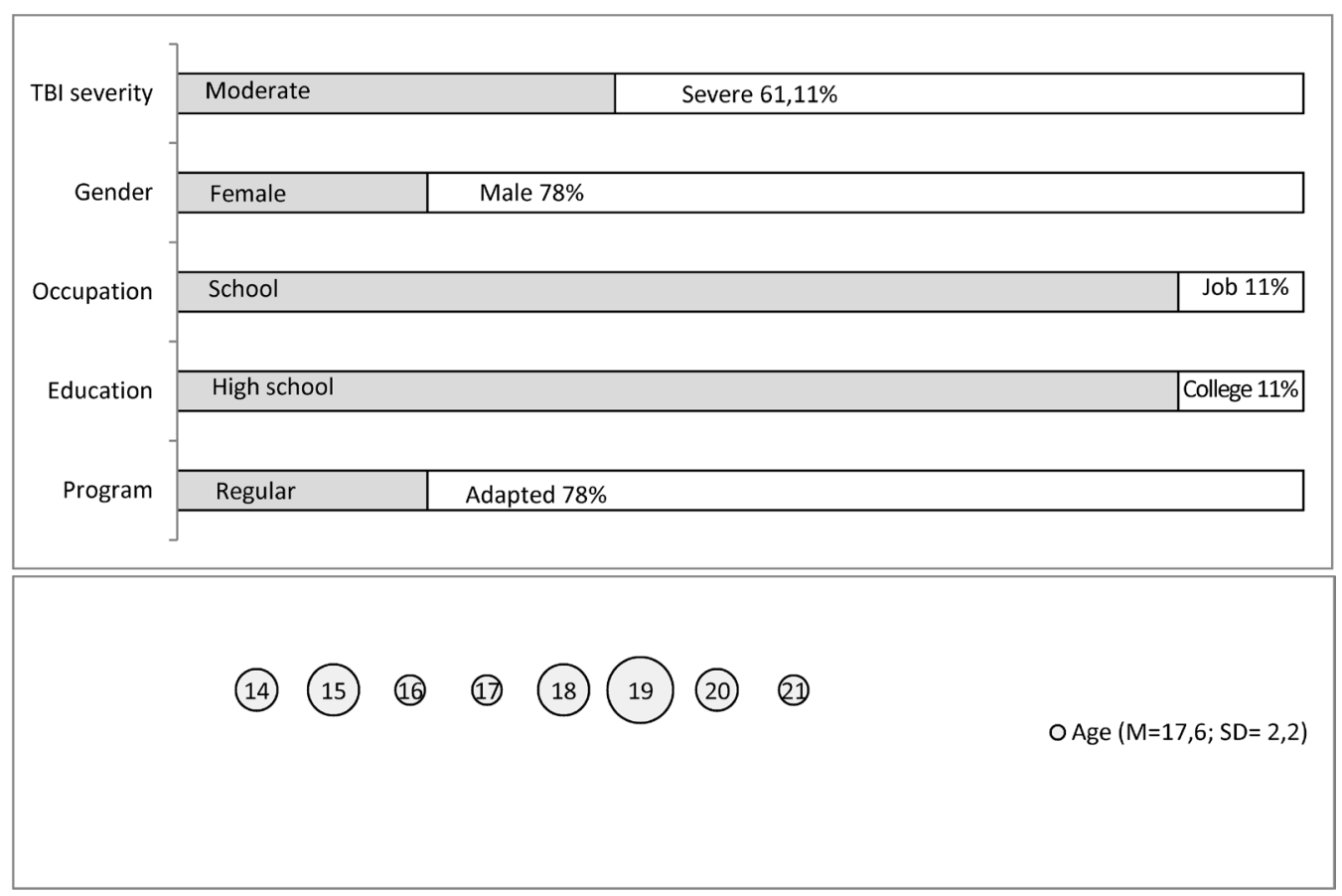

Figure 1. Participants' profiles $(\mathrm{N}=18)$. The larger the circle, the greater the number of participants in this age category.

identity, etc. [24]. This tool is valid and reliable [24,25], and has previously been used among children and adolescents who have suffered a moderate or severe TBI [1]. Each item assesses the degree of accomplishment for each life habit while taking into account: 1) the degree of difficulty to achieve it and 2) the type of assistance required to accomplish it (no assistance, assistive device, adaptation, human assistance). If a specific life habit is not part of the client's current life or lifestyle on the basis of personal choice, this element is considered to be non-applicable in the assessment of handicap or social participation situations. The instrument also has a fivelevel scale evaluating the person's satisfaction with its degree of life habit accomplishments, ranging from very dissatisfied to very satisfied. In order to take into account variations in the number of items included in each life habit category, a normalized score (0 to 10$)$ for each life habit category and for the total score was calculated from the raw scores. This normalized score attributes a relative weight to each life habit category. To calculate this normalized score, the scores of items per category were added and then divided by the number of applicable items.

Given that all the results ranged from 0 to 9 , the normalized score had to then be reported out of 10 or 100 .

In addition to the items selected from the LIFE-H, participants were sub-questioned regarding the reasons for their satisfaction or dissatisfaction with regard to their level of life habit accomplishments and the strategies they feel would improve performance. These sub-ques- tions were formulated as assertions requiring a yes or no response from the participants. Frequency analyses on the reasons evoked by the adolescents for improving satisfaction were conducted on life habits, and the level of performance of the latter that was currently identified as most unsatisfying.

The participants were also questioned as to how they perceive themselves in the future with regard to eight broad life habit categories. Accordingly, using the same LIFE-H scale, the participants indicated how they believe they will perform on the following life habits 10 years from now: meal preparation, communication, transportation, sports and games, education, employment, and interpersonal affective relationships.

At the end of the questionnaire, participants were given the option to respond to 3 open-ended questions enabling them to express their needs without constraint, to prioritize them, or else identify subjects not addressed in the questionnaire.

A socio-demographic questionnaire related to age, sex and educational level was also completed by a parent of each adolescent. TBI severity was established according to the Glasgow Coma Scale and medical diagnosis at the time of admission in the emergency room, as noted in the medical file.

\subsection{Analyses}

As described in the section titled Method, a normalized score was calculated for each life habit and measured by 
way of LIFE-H assessment of each participant. Based on their scores on the Glasgow Coma Scale, participants were then divided into two groups, one of young people with moderate TBIs and the second with severe TBIs. The percentage of the number of participants who reached the same level of achievement for each way of life was then calculated for each group.

Frequency analyses on the satisfaction level of each LIFE-H life habit and groups were conducted. Subsequently, a satisfaction level was identified for each category of achievement of life habits for each group.

Frequency analyses on the strategies evoked by the adolescents to improve satisfaction with life habit performance were also conducted for those habits currently identified as being most unsatisfactory. The reasons identified by more the $25 \%$ of the participants are reported.

For open-ended questions, a verbatim transcript was formulated. A preliminary coding grid was developed based on the themes used in the interview schema. Next, the research team added more precise and structured categories for each of these themes. This grid was submitted to inter-rater agreement procedures involving three professionals who have worked more than 10 years in a trauma program for children and adolescents, in order to ensure the validity and internal consistency of the categories and their mutually exclusive nature. Each of the three judges individually coded six verbatim statements as a first reader, then six verbatim statements as a second reader.

Furthermore, the team ensured that an $80 \%$ inter-rater agreement ratio was obtained. This procedure to ascertain valid inter-rater agreement is recommended by Miles and Shelvin (2001) [26].

\section{RESULTS}

Eighteen adolescents aged 14 to 21 with moderate or severe TBIs participated in this study.

\subsection{Level of Life Habits Accomplishments}

Calculations of the level of life habit accomplishments were conducted. While comparing the level of achievement of life habits of each group, it was revealed that youths with severe TBIs exhibited lower levels than those with a moderate TBI. Among the affected life habits, are Communication: receiving and understanding information in a directory. Leisure: the majority of activities being related to the organization, planning and practicing of sports activities. Interpersonal relations: maintaining relationships with brothers, sisters and friends. Personal responsibilities: managing pocket money and the use of a credit card to make purchases (Figure 2).

Some life habits appear to be disturbed in youths with moderate TBIs as well as for those with severe ones. Within the mobility categories are the following: The use of a bicycle or an automobile. Education: Learning-related activities, as well as those related to vocational training, and home work. Preparing meals and all activities related to work (Figure 3).

\subsection{Satisfaction with Current Life Habit Accomplishments}

Overall analyses of all questioned life habits lead to the identification of specific life habits that revealed some level of dissatisfaction (Figures 2 and 3): Driving a vehicle, participating in sporting and recreational activities, using services provided by a medical clinic, and all activities related to education and work present the highest level of dissatisfaction for both groups of adolescents and young adults with TBIs. Those with severe TBIs reveal a higher level of dissatisfaction, particularly with regard to life habits involving interpersonal relationships.

\subsection{Verbatim Statements}

The analyses of interviews lead to the identification of several life habits that are considered to be priorities by all adolescents. Given the multitude of life habits identified, the judges agreed to group high priority life habits into two categories: The need for autonomy and the need to maintain good interpersonal relationships. For each "need" category, inter-rater agreement enabled identification of related life habits (Table 1). Life habits judged by the participants to be unsatisfying were classified into the categories that best represented them through interrater agreement. In order to attain ideal and complete social participation, youths who have suffered a moderate to severe TBI propose certain strategies to improve their satisfaction levels.

\subsection{Strategies Evoked to Improve Satisfaction Level}

A significant variability was observed related to the means that would improve their satisfaction with life habit accomplishments (Figure 1). The strategies evoked by at least $10 \%$ of the participants are presented in Table 2 . These suggested strategies are mostly attributable to the improvement of external factors: attitudes that are less protective among family and close friends, more knowledge within the social milieu regarding the adolescent's disabilities, or more support from the rehabilitation team to reduce their disabilities.

More specifically, adolescents suggest that for 4 of the 8 unsatisfying life habits, a less protective, close social network would facilitate greater satisfaction and increase performance level. These four life habits are: driving a car, planning games and sports activities, seeking 

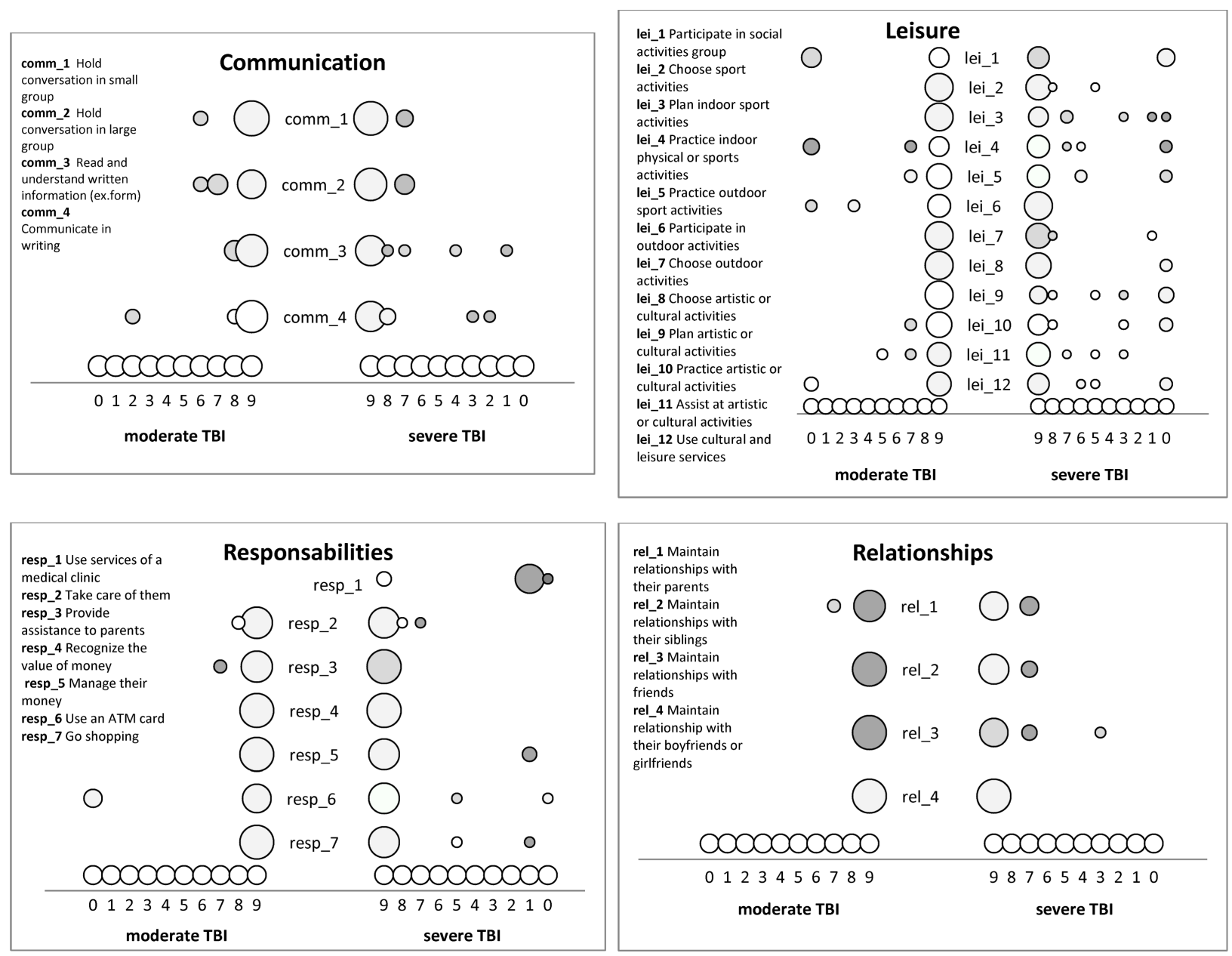

Figure 2. Percentage of each group (the larger the circle, the higher the percentage) according to their level of achievement of life habits ( 9 is optimal level of achievement) and connected to the satisfaction of achieving the life habit (the darker circle, the more life is unsatisfactory).

employment and interpersonal affective relationships.

A need for others to better understand their disabilities, to adapt to these disabilities, and to seek out information about their needs is reported in relation to three of the eight unsatisfying life habits: maintaining a conversation with a small group of persons, holding a paid job and maintaining interpersonal affective relationships. Thus, these findings suggest that the general public be educated about the disabilities and the need for social participation of adolescents and young adults living with a TBI.

Support from a rehabilitation clinician is reported for six life habits: driving a car, planning games and sports, doing homework, seeking employment, holding a paid job and maintaining interpersonal affective relationships. Support from a clinician can take on many forms, whether it is teaching strategies to accomplish a life habit, support for adaptation techniques, or psychological support. However, participants expressed the wish that this support be provided over a short period of time, through hands-on practice of activities outside of the rehabilita- tion centre.

\subsection{Needs to Achieve Full Social Participation in the Future}

The current needs of adolescents and young adults with a moderate or severe TBI fall within a developmental context of adolescence; needs for independence and autonomy, such as those reported among adolescents within the scope of a typical development [2]. Analysis of the findings shows that teenagers and young adults perceive that if their current needs are well met, they will reach full social participation in the future except for education (Figure 4).

Analyses of all data obtained by way of the questionnaires and semi-structured interviews made it possible to identify two broad current "need" categories: autonomy and interpersonal relationships. Adolescents with a moderate to severe TBI expressed that adequate response to these needs would lead to full social participation. 

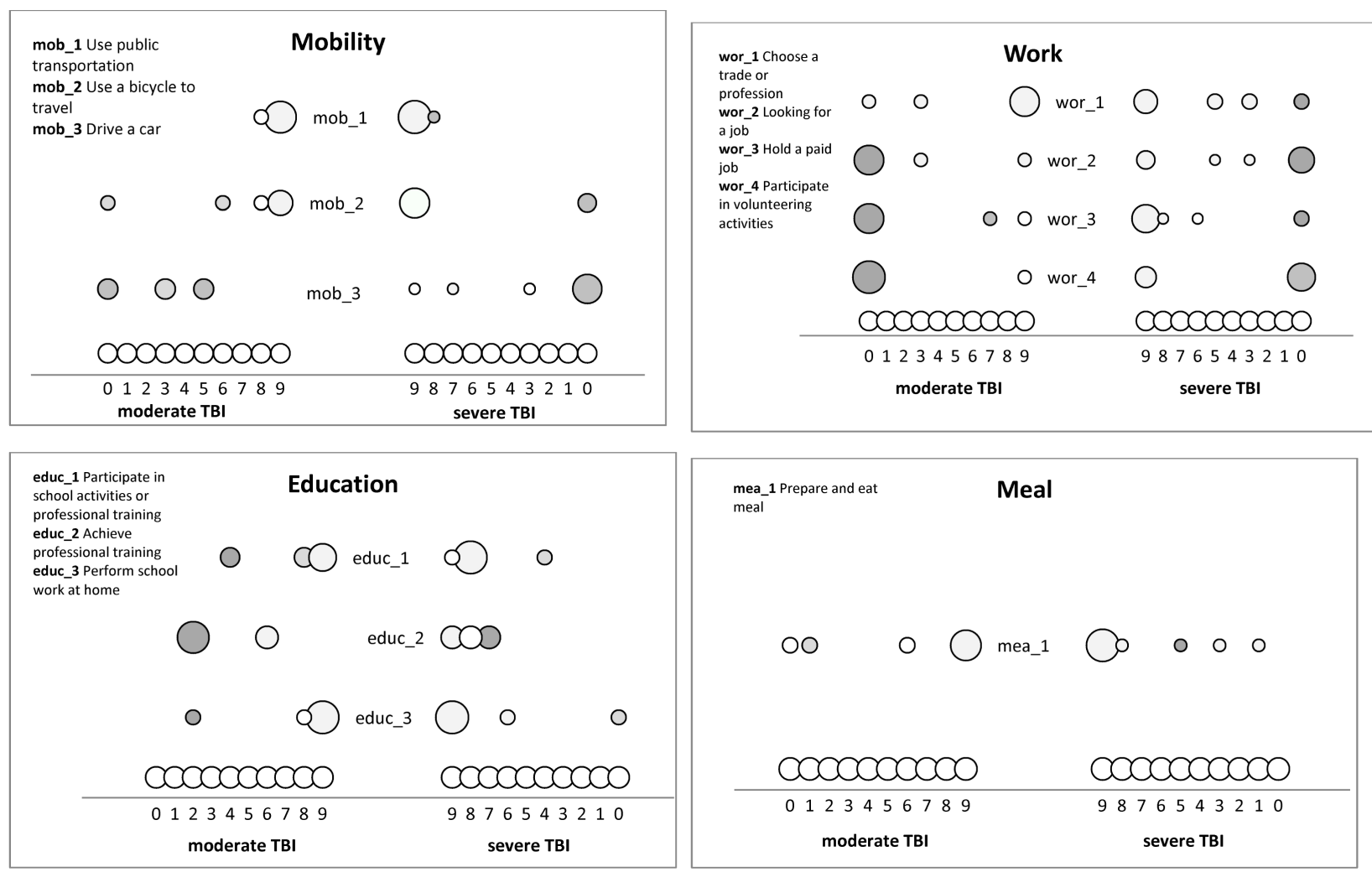

Figure 3. Percentage of each group (the larger the circle, the higher the percentage) according to their level of achievement of life habits ( 9 is optimal level of achievement) and connected to the satisfaction of achieving the life habit (the darker circle, the more life is unsatisfactory).

Table 1. Need categories that are considered to be priorities according to inter-rater agreement and related life habits.

\begin{tabular}{|c|c|c|}
\hline Need Category & Related Life Habits & Verbatim examples \\
\hline $\begin{array}{l}\text { Need for autonomy } \\
\text { and independence }\end{array}$ & $\begin{array}{c}\text { Meal preparation } \\
\text { Mobility } \\
\text { Taking responsibilities } \\
\text { Education } \\
\text { Work } \\
\text { Leisure }\end{array}$ & $\begin{array}{l}\text { "Education is like my future, what I'll be doing later on”. } \\
\text { "If I'm not responsible, well it'll probably cause some problems. Like... if I had to pay my rent and } \\
\text { then... well I forget, they I could be kicked out”. } \\
\text { "You have to know how to get along by yourself for that. Um, cause I wouldn't want to depend on } \\
\text { someone else all the time to make my meals and do my things". }\end{array}$ \\
\hline
\end{tabular}

The following verbatim examples to the question "How do you see yourself in 10 years?" well illustrate their projections into the future:

"Studying and with a part-time job to pay my studies. With a girlfriend. Living in an apartment or maybe a college dorm room.” (16-year-old boy)

"In a relationship with a girl, with a job or maybe studying.” (14-year-old boy)

"Living in an apartment with my boyfriend, with a nice job.” (15-year-old girl)

"I imagine a normal life like everybody else." (14- year-old boy)

"With kids, with a family". (18-year-old boy)

"In 10 years, I'll be all better and will live like everybody else does.” (15-year-old boy)

\subsection{Projected Level of Life Habit Accomplishments in the Future}

Analyses of adolescents' perceptions of their level of life habit accomplishments in the future makes it possible to identify how they foresee their performance related to general life habits in adulthood (Figure 4). The 
Table 2. Unsatisfying life habits and strategies evoked by participants to improve satisfaction level.

\begin{tabular}{|c|c|}
\hline Life habit & Strategies \\
\hline Conversation within a small group & That conversation partners leave more room for them to participate. \\
\hline Driving a car & $\begin{array}{l}\text { Have more information and support for obtaining a driver's license. } \\
\text { More driving practice with an instructor. } \\
\text { Have more driving preparation activities at home. } \\
\text { Being allowed to practice driving with parents' car. } \\
\text { Obtain permission from the rehabilitation team to get a driver's license more quickly. }\end{array}$ \\
\hline & Have parents who better understand my situation and who are less protective. \\
\hline Planning sports activities & $\begin{array}{l}\text { Have parents and the rehabilitation team inform them of activities that are accessible to them. } \\
\text { Have parents and the rehabilitation team propose adapted and non-adapted activities. }\end{array}$ \\
\hline Perform school work at home & $\begin{array}{l}\text { Obtain support studying at home (e.g. revision support, methods to memorise information and to improve } \\
\text { concentration, practice oral presentations). }\end{array}$ \\
\hline Activities for looking for a job & $\begin{array}{l}\text { Have the support of a rehabilitation clinician to prepare for steps related to employment. } \\
\text { Have greater parents' comprehension and have more autonomy in conducting these activities. } \\
\text { Meet with other adolescents to prepare for job searches. }\end{array}$ \\
\hline Holding a paying job & $\begin{array}{l}\text { Have the adaptations necessary to compensate for motor disabilities. } \\
\text { Have psychological support for explaining one's needs to the employer. } \\
\text { Have employers and colleagues who better understand one's needs and disabilities through psychoeducation } \\
\text { provided by rehabilitation clinicians. } \\
\text { Be accompanied by a clinician during one's first day on the job. }\end{array}$ \\
\hline $\begin{array}{l}\text { Relationships with parents } \\
\text { and siblings }\end{array}$ & $\begin{array}{l}\text { Have more family activities. } \\
\text { Have a family that is better informed of my needs, disabilities, and feelings. } \\
\text { Have a less protective family. } \\
\text { Have a family that better understands my needs. } \\
\text { Receive professional help to discuss one's relationships with family. } \\
\text { Receive professional help for discussing family relationships in the presence of one's family. }\end{array}$ \\
\hline
\end{tabular}

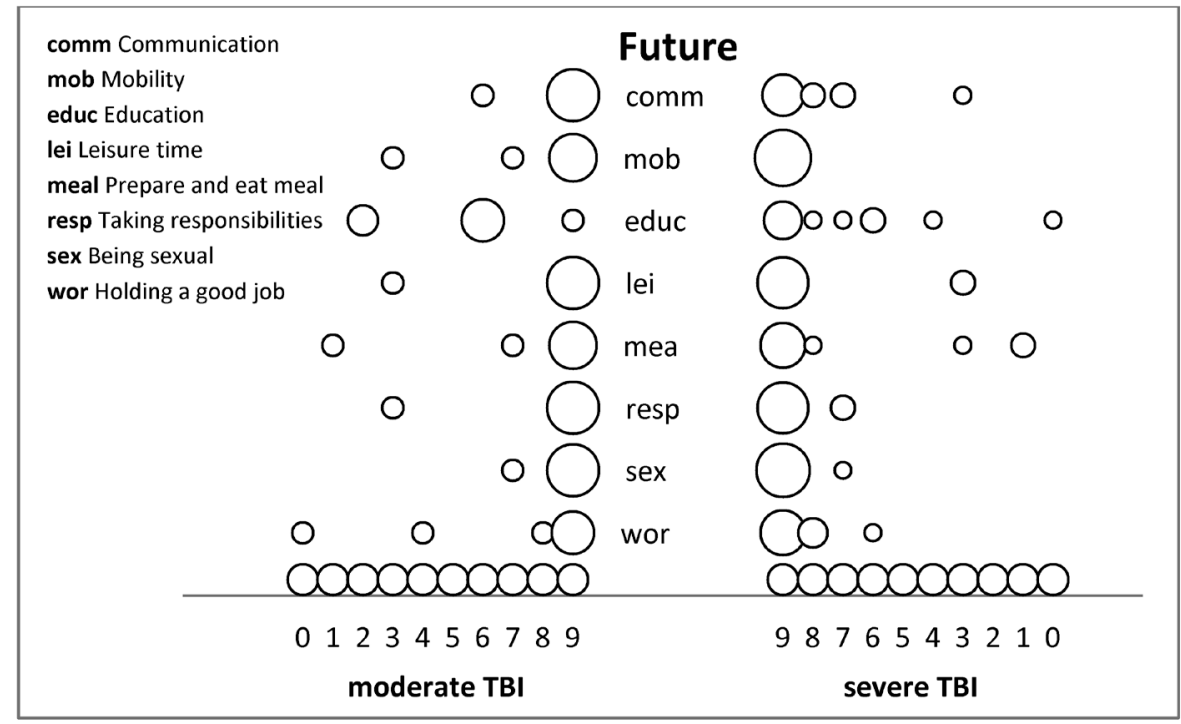

Figure 4. Percentage of each group (the larger the circle, the higher the percentage) according to their level of achievement of life habits that they envision in the future ( 9 is optimal level of achievement).

findings suggest that contrary to their current accomplishment levels presented in Figures 2 and 3, a high projection of life habit accomplishment was generated, except for the "Education" life habit, which was projected to be less accomplished and which presented greater variability in expected levels of accomplishments.

\section{DISCUSSION}

The general objective of this study was to identify the specific needs of adolescents and young adults aged 14 to 20, who have suffered a moderate or severe TBI, with regard to their current level of life habit accomplishments and the means that would enable them to improve 
their performance on those life habits considered most unsatisfying. It also aimed to examine how these same individuals see themselves in the future.

\subsection{Impact of the Level of Severity}

It is recognized that the severity of a TBI affects the recovery of cognitive functions [8]. It also seems that it has an impact on the achievement of certain life habits $[4,5]$. Some of those habits appear to be disturbed in youths with moderate as well as those with severe TBIs, such as using a bicycle or a car, engaging in activities related to learning, vocational training, homework assignments, the preparation of meals and all activities related to work. The findings also indicated that some life habits are more disturbed for young people with severe TBIs, primarily in terms of communication: entertainment, most activities related to organizing, planning and the practice of sports activities, interpersonal relationships e.g. maintaining relationships with friends and siblings as well as responsibilities like managing pocket money, using a credit card and making purchases.

Furthermore, both groups of adolescents and young adults with TBIs identified autonomy and independence, as well as maintaining good interpersonal relationships as being of the highest priority. They also spoke of strategies to improve upon their dissatisfactions such as psycho- education for family and friends and training for specific activities within their living environment. They also foresaw themselves as attaining full social participation in the future, same as any other adolescent of the same age.

It is known that a moderate or severe TBI, with its physical, cognitive, emotional and behavioral sequels, affects normal development of the adolescent with regard to body image, peer group identification, autonomy and independence [27]. However, even if parents and adolescents agree on the psychosocial outcome [28], it appears that despite disruptions to normal development as a consequence of their TBIs, they are able to clearly identify their current needs and to see themselves in adulthood and in the future as experiencing few difficulties to accomplish their life habits.

\subsection{Needs for Autonomy and Independence}

The future foreseen by these adolescents and young adults with moderate or severe TBIs encompasses full social participation, which consequently puts their current need for autonomy and independence above all else. It also highlights the importance of identifying unsatisfied life habits that currently hinder fulfillment of this need. It is possible that during adulthood the need for autonomy and independence is associated with an independent life within a home independent of one's parents. Consequently, the need to ensure this independence takes on great importance, notably with regard to mobility. Mobility, largely represented by driving an automobile, appears to be the life habit of greatest concern among adolescents who have suffered moderate or severe TBIs. Driving an automobile, riding a bicycle, taking on responsibilities represent some of the major means to become autonomous and are in fact recognized as being factors predicting good community integration following a TBI [29]. Moreover, other life habits that were considered not to be satisfied were directly related to the need to meet their financial needs in adulthood and thus associated with current needs for support in completing homework, as well as those related to seeking and maintaining employment. Moreover, our current society reinforces the need to engage in leisure activities as a means of community integration. Therefore, planning leisure activities is also an aspect of social integration. Indeed, taking part in leisure activities greatly favors the sociocommunity integration of people who have suffered a TBI. Interestingly, youths also report that the balance between work and their personal lives depends upon leisure activities and good interpersonal relationships.

\subsection{Needs Relating to Maintaining Good Interpersonal Relationships}

According to results of the LIFE-H, interpersonal relationships are not among those life habits not satisfactorily accomplished. However, verbatim analysis shows that they are of significant concern for adolescents, particularly the need to maintain good relationships with family both now and in the future. This was a more important issue for those with severe TBIs.

The participants with TBI report being preoccupied by maintaining good interpersonal relationships, not only with parents and siblings, but also with peers. Based on their verbatim notions of communication to maintain good interpersonal relationships, this need is fulfilled via the "communication" life habit. Interpersonal relationships with parents and support parents who provide for the youngsters who have suffered a moderate or severe TBI are paramount to facilitate adequate long term sociocommunity integration and satisfying social participation [30,31].

Moreover, the need to maintain good interpersonal relationships seems to be largely related to social skills, which appear to be deficient among adolescent clients who have suffered a TBI and yet so important in the accomplishment of life habits [32]. A neuroscientific study of social competence that is supported by neurological bases among a population of children who have suffered a TBI is now emerging [33,34]. These authors propose a model that characterizes the social relationships of this population. They link social adjustment, peer interaction, social problem solving and the neurological substrates 
that underlie each of these actions among children and adolescents whose brains are developing. Their model implies that neurological impairment of a child or adolescent with a TBI will affect the social competency sphere. For this reason, these significant variables are integral factors of our model and modulate the needs of adolescents with a moderate to severe TBI even though the study participants' TBI severity, developmental age and neurological sequelae were not specifically documented within this study.

\subsection{Strategies to Improve Life Habit Accomplishment}

Youths who have suffered a moderate or severe TBI are able to generate strategies to facilitate the accomplishment of life habits judged to be most unsatisfying and aim to achieve better social participation. Firstly, they identified the need for psychoeducation for their immediate entourage such as family and friends and social contacts such as teachers and coaches, in order for their network to be more familiar with their disabilities, their needs, and the impact of these disabilities on the accomplishment of their life habits. These psychoeducational needs correspond to those identified by families themselves $[35,36]$. Adolescents with moderate or severe TBIs would also like their families and friends to behave less protective and to let them experience their lives like other adolescents. Moreover, these adolescents also identify the need for support from the rehabilitation centre team, ideally in the form of training for specific activities e.g. driving an automobile, preparing meals, to compensate for their disabilities that take place within their living environments i.e. school and home, rather than in the rehabilitation centre, preferably over a short period of time. As can be noted, adolescents who have experienced a moderate or severe TBI demand services and support that correspond well to a holistic reeducation model such as that proposed to the adult clientele by Keith D. Cicerone's team $[37,38]$. This 16 -week holistic intervention model focuses on cognitive rehabilitation as applied to both social and professional functional tasks. Given the training needs identified by adolescents who have suffered a moderate or severe TBI, it would be relevant to apply and study its impact on this clientele. Indeed, it would probably respond well to their needs for intensive intervention focusing on life habits and targeting full social participation in the future.

\subsection{Needs Identified for the Future}

A youngster with a moderate or severe TBI imagines accomplishing its life habits without any difficulties in the near future; this situation is also observed in other groups of adolescents with disabilities where they share the same aspirations regarding the future as those without disabilities [39]. Only the life habit relating to education is perceived by adolescents and young adults to be potentially disrupted in the future. According to the authors, this can be explained by the fact that this life habit is currently quite present in the daily lives of adolescents and that it is possibly impaired given the diverse cognitive sequelae that are generally documented among people who have suffered a TBI [8] and which can also cause learning and scholastic integration difficulties [40]. As such, adolescents foresee the impact of their disrupted "education" life habit in the future, which reinforces the relevance of their documented education support needs [41-43]. Indeed, it can be observed in their verbatim statements that education takes on three different meanings. First, it is associated with scholastic and professional orientation. Secondly, it is associated with learning social conventions. Finally, education is perceived as being important for ensuring a promising future and occupation. It thus appears paramount to validate what he or she is referring to when discussing their educational needs, when working with a young adult with a moderate or severe TBI,

"Education is important if you want to get a job and have money to pay for leisure activities and to have fun."

"Education, well it's important because... culture, you know knowledge, it's important, you know... not necessarily just school, but you need to learn in life, you need to know things."

"Education, well it's important to learn things and to not let a charming TBI ruin your life... I think it's pretty important.”

\section{CONCLUSION}

Adolescents and young adults with a moderate or severe TBI see themselves in the future as having few difficulties and achieving full social participation, same as other adolescents at their age. To be able to attain this level of life habit accomplishment, they note certain current dissatisfactions with regard to the accomplishment of their life habits and are able to identify certain means to achieve them. This study further reveals findings obtained by Gagnon and colleagues [15] whose study aimed to identify the needs of adolescents who have suffered a mild TBI. Although neuropsychological measures were not used as a variable in this study, it is clear that the severity of the TBI, with its neurocognitive consequences, modulates the needs of adolescents who have suffered a TBI. Parents could identify the quality-of-life of their brain injured adolescents [28] but it seems interesting and important to the asked adolescents themselves. Youngsters with a severe TBI are more perturbed with regard to the accomplishment of life habits, in particular 
related to communication, planning and practicing sport activities and interpersonal relationships. This is not surprising, since the severity of TBIs is also a good predictor of functional recovery and quality of life among youths with moderate or severe TBIs [5,8]. For this reason, the support and information needs identified earlier by Gagnon et al. study appear to us to be encompassed by the current needs for autonomy and the maintenance of good interpersonal relationships, both of which are related to unsatisfying levels of life habit accomplishments. Providing the social network with tools to better support the youths, providing psychoeducation within the living environments regarding services accessible through rehabilitation, as well as providing better intensive services within the living environment that focus on functional activities, appear to be interventions that should be investigated and developed among adolescent and young adult clients who have suffered a moderate or severe TBI.

\section{ACKNOWLEDGEMENTS}

We would like to thank the Elan Foundation for its financial contribution and Michel Desaulniers, Mario Cloutier, Thérèse Brousseau, Julie Beaulieu and Isabelle Deaudelin for their support.

\section{REFERENCES}

[1] Lamontagne, M.-E., Ouellet, M.-C. and Simard, J.-F. (2009) A descriptive portrait of human assistance required by individuals with brain injury. Brain Injury, 23, 693701. http://dx.doi.org/10.1080/02699050902970760

[2] Turskra, L.S. (2000) Should my skirt be tucked in or left out? The communication context of adolescence. Aphasiology, 14, 349-364. http://dx.doi.org/10.1080/026870300401405

[3] Brenner, L.A., Dise-Lewis, J.E., Bartles, S.K., O’Brien, S.E., Godleski, M. and Selinger, M. (2007) The long-term impact and rehabilitation of pediatric traumatic brain injury: A 50-year follow-up case study. Journal of Head Trauma rehabilitation, 22, 56-64. http://dx.doi.org/10.1097/00001199-200701000-00007

[4] Van Tol, E., Gorter, J.W., DeMatteo, C. and MeesterDelver, A. (2011) Participation outcomes for children with acquired brain injury: A narrative review. Brain Injury, 25, 1279-1287. http://dx.doi.org/10.3109/02699052.2011.613089

[5] Anaby, D., Law, M., Hanna, S. and Dematteo, C. (2012) Predictors of change in participation rates following acquired brain injury: Results of a longitudinal study. Developmental Medicine and Child Neurology, 54, 339-346. http://dx.doi.org/10.1111/j.1469-8749.2011.04204.x

[6] Coleman, J.C. and Hendry L.B. (1999) The nature of adolescence. 3rd Edition, Routledge, New York.

[7] Soo, C., Tate, R.L., Anderson, V. and Waugh, M.-C. (2010) Assessing care and support needs for children with acquired brain injury: Normative data for the paediatric care and needs. Brain Impairment, 4, 183-196.

http://dx.doi.org/10.1375/brim.11.2.183

[8] Anderson, V.A., Catroppa, C., Dudgeon, P., Morse, S.A., Haritou, F. and Rosenfeld, J.V. (2006) Understanding predictors of functional recovery and outcome 30 months following early childhood head injury. Neuropsychology, 20, 42-57. http://dx.doi.org/10.1037/0894-4105.20.1.42

[9] Rivara, F.P., et al. (2011) Disability 3, 12, and 24 months after traumatic brain injury among children and adolescents. Pediatrics, 128, e1129-e1138. http://dx.doi.org/10.1542/peds.2011-0840

[10] Ewing-Cobbs, L., Prasad, M., Fletcher, J., Levin, H.S., Miner, M.E. and Eisenberg, H.M. (1998) Attention after pediatric traumatic brain injury: A multidimensional assessment. Child Neuropsychology, 4, 35-40. http://dx.doi.org/10.1076/chin.4.1.35.3194

[11] Hanten, G., Bartha, M. and Levin, H.S. (2000) Metacognition following pediatric traumatic brain injury: A preliminary study. Developmental Neuropsychology, 18, 383-398. http://dx.doi.org/10.1207/S1532694206Hanten

[12] Taylor, H.G., Yeates, K.O., Wade, S.L., Drotar, D., Stancin, T. and Minich, N.A. (2002) Prospective study of short- and long-term outcomes after traumatic brain injury in children: Behavior and achievement. Neuropsychology, 16, 15-27.

http://dx.doi.org/10.1037/0894-4105.16.1.15

[13] Fougeyrollas, P., Cloutier, R., Bergeron, H., Côté, J. and St-Michel, G. (1998) Classification québécoise. Processus de production du handicap. RIPPH/SCCIDIH, Québec.

[14] Gauvin-Lepage, J. and Lefebvre, H. (2010) Social inclusion of persons with moderate head injuries: The points of view of adolescents with brain injuries, their parents and professionals. Brain Injury, 24, 1087-1097. http://dx.doi.org/10.3109/02699052.2010.494593

[15] Gagnon, I., Swaine, B., Champagne, F. and Lefebvre, H. (2008) Perspectives of adolescents and their parents regarding service needs following a mild traumatic brain injury. Brain Injury, 22, 161-173. http://dx.doi.org/10.1080/02699050701867381

[16] Rotondi, A.J., Sinkule, J., Balzer, K., Harris, J. and Moldovan, R. (2007) A qualitative needs assessment of persons who have experienced traumatic brain injury and their primary family caregivers. Journal of Head Trauma Rehabilitation, 22, 14-25. http://dx.doi.org/10.1097/00001199-200701000-00002

[17] Heinemann, A.W., Sokol, K., Garvin, L. and Bode, R.K. (2002) Measuring unmet needs and services among persons with traumatic brain injury. Archives of Physical and Medical Rehabilitation, 83, 1052-1059. http://dx.doi.org/10.1053/apmr.2002.34283

[18] Lefebvre, H. and Levert, M.-J. (2012) The close relatives of people who have had a traumatic brain injury and their special needs. Brain Injury, 26, 1084-1087. http://dx.doi.org/10.3109/02699052.2012.666364

[19] Corrigan, J.D. (2001) Conducting statewide needs assessments for persons with traumatic brain injury. Journal 
of Head Trauma Rehabilitation, 16, 1-19. http://dx.doi.org/10.1097/00001199-200102000-00004

[20] Brooks, C.A., Gabella, B., Hoffman, R., Sosin, D. and Whiteneck, G. (1997) Traumatic brain injury: Designing and implementing a population-based follow-up system. Journal of Head Trauma Rehabilitation, 78, s26-s30.

[21] Gervais, M. and Dubé, S. (1999) Étude exploratoire des besoins en services offerts à la clientèle traumatisée cranio-cérébrale au Québec. Research Dissertation, Laval University and Institut de Réadaptation en Déficience Physique de Québec, Quebec City.

[22] Petersen, C., Scherwath, A., Fink, J. and Koch, U. (2008) Health care needs of children and adolescents with a traumatic brain injury. Bundesgesundheitsblatt, Gesundheitsforschung, Gesundheitsschutz, 51, 629-636. http://dx.doi.org/10.1007/s00103-008-0536-3

[23] Société de l'Assurance Automobile du Québec (2008) Bilan routier. Quebec Governement, Quebec City.

[24] Noreau, L. (2004) Measuring social participation: Reliability of the LIFE-H in older adults with disabilities. Disability and Rehabilitation, 26, 346-352. http://dx.doi.org/10.1080/09638280410001658649

[25] Fougeyrollas, P., Noreau, L. and St-Michel, G. (1997) Measure of life habits: User's manual. International Network on the Disability Creation Process, Quebec City.

[26] Miles, J. and Shelvin, M. (2001) Applying regression and correlation: A guide for students and researchers. Sage, London.

[27] Turkstra, L.S. (2008) Conversation-based assessment of social cognition in adults with traumatic brain injury. Brain Injury, 22, 397-409. http://dx.doi.org/10.1080/02699050802027059

[28] Green, L., Godfrey, C., Soo, C., Anderson, V. and Catroppa, C. (2012) Agreement between parent-adolescent ratings on psychosocial outcome and quality-of-life following childhood traumatic brain injury. Developmental Neurorehabilitation, 15, 105-113. http://dx.doi.org/10.3109/17518423.2011.638331

[29] Rapport, L.J., Bryer, R.C. and Hanks, R.A. (2008) Driving and community integration after traumatic brain injury. Archives of Physical Medicine Rehabilitation, 89, 922-930. http://dx.doi.org/10.1016/j.apmr.2008.01.009

[30] Lefebvre, H., Cloutier, G. and Levert, M.-J. (2008) Perspectives of survivors of traumatic brain injury and their caregivers on long-term social integration. Brain Injury, 22, 535-543. http://dx.doi.org/10.1080/02699050802158243

[31] Rosema, S., Crowe, L. and Anderson, V. (2012) Social function in children and adolescents after traumatic brain injury: A systematic review 1989-2011. Journal of Neurotrauma, $\mathbf{2 9}, 1277-1291$. http://dx.doi.org/10.1089/neu.2011.2144

[32] Willemse-van Son, A.H., Ribbers, G.M., Hop, W.C. and Stam, H.J. (2009) Community integration following moderate to severe traumatic brain injury: A longitudinal in- vestigation. Journal of Rehabilitation Medicine, 41, 521527. http://dx.doi.org/10.2340/16501977-0377

[33] Beauchamp, M.H. and Anderson, V. (2010) SOCIAL: An integrative framework for the development of social skills. Psychological Bulletin, 136, 39-64. http://dx.doi.org/10.1037/a0017768

[34] Yeates, K.O., et al. (2007) Social outcomes in childhood brain disorder: A heuristic integration of social neuroscience and developmental psychology. Psychological Bulletin, 133, 535-556.

http://dx.doi.org/10.1037/0033-2909.133.3.535

[35] Cole, W.R., Paulos, S.T., Cole, C.A.S. and Tankard, C. (2009) A review of family intervention guidelines for pediatric acquired brain injuries. Developmental Disabilities Research Reviews, 15, 159-166. http://dx.doi.org/10.1002/ddrr.58

[36] Ponsford, J., Olver, J., Ponsford, M. and Nelms, R. (2003) Long-term adjustment of families following traumatic brain injury where comprehensive rehabilitation has been provided. Brain Injury, 17, 453-468. http://dx.doi.org/10.1080/0269905031000070143

[37] Cicerone, K.D., et al. (2008) A randomized controlled trial of holistic neuropsychologic rehabilitation after traumatic brain injury. Archives of Physical Medicine Rehabilitation, 89, 2239-2249. http://dx.doi.org/10.1016/j.apmr.2008.06.017

[38] Cicerone, K.D., Mott, T., Azulay, J. and Friel, J.C. (2004) Community integration and satisfaction with functioning after intensive cognitive rehabilitation for traumatic brain injury. Archives of Physical Medicine Rehabilitation, 85, 943-950. http://dx.doi.org/10.1016/j.apmr.2003.07.019

[39] Burchardt, T. (2004) Aiming high: The educational and occupational aspirations of young disabled people. Support for Learning, 19, 181-186. http://dx.doi.org/10.1111/j.0268-2141.2004.00345.x

[40] Anderson, V., Brown, S., Newitt, H. and Hoile, H. (2009) Educational, vocational, psychosocial, and quality-of-life outcomes for adult survivors of childhood traumatic brain injury. Journal of Head Trauma Rehabilitation, 24, 303312. http://dx.doi.org/10.1097/HTR.0b013e3181ada830

[41] Glang, A., Todis, B., Thomas, C.W., Hood, D., Bedell, G. and Cockrell, J. (2008) Return to school following childhood TBI: Who gets services? NeuroRehabilitation, 23, 477-486.

[42] Todis, B., Glang, A., Bullis, M., Ettel, D. and Hood, D. (2011) Longitudinal Investigation of the post-high school transition experiences of adolescents with traumatic brain injury. Journal of Head Trauma Rehabilitation, 26, 138149. http://dx.doi.org/10.1097/HTR.0b013e3181e5a87a

[43] Souza, L.M.N., Braga, L.W., Filho, G.N. and Dellatolas, G. (2007) Quality-of-life: Child and parent perspectives following severe traumatic brain injury. Developmental Neuroprehabilitation, 10, 35-47. http://dx.doi.org/10.1080/13638490600822239 